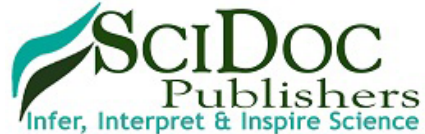

\section{International Journal of Dentistry and Oral Science (IJDOS) ISSN: 2377-8075}

\title{
Natal Teeth - A Case Report
}

Case Report

Nadhirah Faiz ${ }^{1}$, Mebin Mathew George $e^{2 *}$

${ }^{1}$ Department of Prosthodontics, Saveetha Dental College and Hospitals, Saveetha Institute of Medical and Technical Sciences, Saveetha University, Chennai, 600077, Tamil Nadu, India.

${ }^{2}$ Senior Lecturer, Department of Pedodontics and Pediatric Dentistry, Saveetha Dental College and Hospitals, Saveetha Institute of Medical and Technical Sciences, Saveetha University, Chennai, 600077, Tamil Nadu, India.

\section{Abstract}

Background: A new addition of a family member usually calls for celebration and every "first" of this newborn is an occasion to be commemorated. Having this at mind, there are certain timelines along which any activity occurring can be considered as normal and any deviation from this can be a reason to cause worry amongst the family. One such phenomenon is the presence of natal and neonatal teeth. It's important to be aware of such phenomena, what the etiology is and how is it to be treated. Conclusion: Pediatric dentists should make every effort to educate the parents and the general public on the etiology and clear their myth related to it. We should be aware of the various treatment options and when to apply it.

Keywords: Natal Teeth; Newborn; Pediatric Dentistry.

\section{Introduction}

An arrival of newborn into a family is filled with immense joy and [1] the early doing's and sayings' of a child is always flooded with immense pleasure [2]. One among which is the eruption of the first teeth of the child. Its an established fact that this phenomenon is seen roughly around 6 month of child's life leading to functional and psychological changes in the child's life, and an emotional event for the parents [1]. However everything has exceptions and an early eruption of teeth in child's mouth or presence of one since birth leads to plethora of reactions [2].

Presence of natal and neonatal teeth is not a new to human kind [2]. It was first documented during Roman times by Titus Livius, in $59 \mathrm{BC}$ and Gaius Plinius Secundus (the Elder), in 23 BC, [3] in the cuneiform inscriptions found at Nineveh an ancient city on the eastern bank of the Tigris river in ancient Assyria [4] and was believed that a splendid future awaited male infants with natal teeth [3]. Variations exist among the belief and superstitions from about such children being doomed or exceptionally favored by fate. Historical figures, such as Richard III, Louis XIV, Napoleon, Mirabeau, Mazarin, Cardinal Richelieu, Zoroaster and Hannibal, fall in the later category. Thoughts differ according to different countries; in England it is believed that infants born with natal teeth are destined to be famous soldiers [4] which was evident by Shakespeare writing in "King Henry the Sixth" where refers to Richard the Third in his quotation, "teeth hadst thou in thy head when thou wast born to riguity thou camest to bite the word." [2] While in france and Italy they are regarded as future conquerors of the world [4] and In Malaysian communities, a natal tooth is believed to herald good fortune [2]. On the contrary in China, Poland, India and Africa, affected children were considered monsters and bearers of misfortune. Allwright reported a case in China where extraction was requested so that the tooth, together with the "attending evil spirits", could be disposed of in the middle of Hong Kong Harbor [4].

Synomyms to natal teeth are Dentitia praecox, dens cannatalis, congenital teeth [2], fetal teeth, predeciduous teeth, precocious dentition (Mayhall and Bodenhoff) [5], infancy teeth [3] (the teeth which erupt after 30 days and much before their normal time of eruption usually one to three and half months after birth are termed as early infancy teeth)[1]

\section{Classification}

The terms natal and neonatal tooth proposed by Massler and Savara (1950) were limited only to the time of eruption and not to

\section{*Corresponding Author:}

Mebin Mathew George,

Senior Lecturer, Department of Pedodontics and Pediatric Dentistry, Saveetha Dental College and Hospitals, Saveetha Institute of Medical and Technical Sciences, Saveetha University, Chennai, 600077, Tamil Nadu, India.

E-mail: mebingmathew@gmail.com

Received: April 107, 2021

Accepted: September 20, 2021

Published: September 21, 2021

Citation: Nadhirah Faiz, Mebin Mathew George. Natal Teeth - A Case Report. Int J Dentistry Oral Sci. 2021;8(9):4403-4406. doi: http://dx.doi.org/10.19070/2377-8075-21000896

Copyright: Mebin Mathew George ${ }^{\oplus}$ 2021. This is an open-access article distributed under the terms of the Creative Commons Attribution License, which permits unrestricted use, distribution and reproduction in any medium, provided the original author and source are credited. 
the anatomical, morphological and structural characteristics thus there was a need for new and detailed classification.

In 1966 Spoug and Feasby came up with this new classification which described natal and neonatal teeth according to their degree of maturity.

1. A mature natal or neonatal tooth is the one which is nearly or fully developed and has relatively good prognosis for maintenance.

2. The term immature natal or neonatal teeth, on the other hand, imply a tooth with incomplete or substandard structure; it also implies a poor prognosis.

Yet another classification was given by Hebling in the year of 1997 depending on appearance of each natal tooth into the oral cavity as the teeth merge into the oral cavity.

1. Shell-shaped crown poorly fixed to the alveolus by the gingival tissue and absence of a root.

2. Solid crown poorly fixed to the alveolus by the gingival tissue and little or no root.

3. Eruption of the incisal margin of the crown through the gingival tissues.

4. Edema of the gingival tissue with an unerupted but palpable tooth.

If the natal teeth of category (1) or (2) shows mobility is more than $2 \mathrm{~mm}$ then usually extraction is needed.(2)

\section{Prevalence}

In class mammaleruption of the lower deciduous incisors is normal at birth but rare in humans [4]. Natal teeth erupt in utero while neonatal teeth appear during the first 1 month of life. Their incidence ranges from 1:2,000 to 1:3,500 live births [6]. Natal teeth are more frequent, approximately three times more common than neonatal teeth [5]. Leung studied 50,892 infants delivered over 17 years and found the incidence of natal teeth to be 1:3,392 live births [4]. There is no sex prediction however female is more common $(66 \%)$ [1]. The race common affected are American Indian tribes also Muslim children exhibited more natal/ neonatal teeth as compared to Hindu children [5].

A high prevalence of natal/neonatal teeth among both unilateral $(2.02 \%)$ and bilateral $(10.06 \%)$ cleft lip and palate and in case of unilateral cleft lip it was $1.98 \%$ and $2.8 \%$ as reported by de Almeida and Gomide from Brazil [7].

\section{Etiology}

The cause for the presence of this common biological chronology is still unknown. However the predicted causes can -general or syndromic. Following are some of the general cause.

1. "Genetic blueprint," i.e. hereditary transmission of a dominant autosomal gene appears to be an important factor to determine the rate at which teeth erupts [2]. Bodenhoff and Gorlin in a study had verified that $15 \%$ showing genetic connection whereas in survey done in Alaska out of all Tlingit Indians children having natal and neonatal teeth $62 \%$ had family history of same condition. In 1950 Massler and Savara and in 1961 Gardiner traced a hereditary factor in 10 out of 24 cases and 7 out of 19 of natal teeth respectively. Halls (1957) reports a family of three brothers where 2 were affected and Hyatt reported 5 siblings born with the condition. On the contrary Allwright (1958) discussed a series of 26 cases in Chinese babies in Hongkong, in only one of which showed hereditary influence [5].

2. Endocrine disturbances: for example excessive secretion from glands like pituitary, thyroid, or gonads [2].

3. Jasmin and Clergeau-Guerithault suggested increased osteoblastic activity within the area of the tooth germ could be a reason [5].

4. Condition like poor maternal health, endocrine disturbances, febrile episodes, exanthemata, pyelitis during pregnancy, and congenital syphilis leads to nutritional deficiency, especially, hypovitaminosis can be triggering factor

5. The most acceptable theory is based upon the result of a superficial localization of the tooth germ [2].

6. Toxic polyhalogenated aromatic hydrocarbons: PCBs, PCDDs, and PCDFs can be the etiology as they have the ability to cross the placenta [3]. Gladen et al. reported that 13 (10\%) of 128 infants born to mothers who were heavily exposed to polychlorinated biphenyls and dibenzofurans during the Yusheng environmental accident in Taiwan had natal teeth [4]. Apart from that these children usually show other associated symptoms such as dystrophic finger nails, hyperpigmentation, etc., probably related to the hereditary factor [2].

Syndromes in which natal teeth can be seen are - Chondroectodermal Dysplasia [8] or Ellis-Van.

\section{Clinical Features}

Clinically they are small (Bigeard et al) or of normal size; conical or of normal shape with small root. The crown shows brownyellowish/whitish opaque color with immature appearance with enamel hypoplasia. They are attached to a pad of soft tissue above the alveolar ridge, occasionally covered by mucosa, which along with short root give rise to exaggerated mobility [2]. Seldom natal teeth followed by premature eruptionof other teeth which indicate that the early eruption is dueto some local disturbance of growthand development [8].

\section{Diagnosis}

The diagnosis of these teeth is very important which is done on the basis of complete history, physical examination of the infant, and by clinical and radiographic findings to judge to which set the teeth belong to - normal dentition or supernumerary; to prevent indiscriminate extractions. This differential is done easily based on the radiographic examination (periapical or occlusal radiographs); presence or absence of a tooth germ in the primary dentition determine whether or not later belongs to normal dentition. However one may face difficulty in properly positioning the film in the mouth of a newborn, thus limiting its application. Another fact is, at this stage of growth and development; primary teeth are undergoing initiation of crown calcification and make the interpretation complicated. At times, it would be best to defer the radiographic exam [6]. A proper examination of surrounding area should also be done bcause it can reveal a relationship between a natal/neonatal tooth, adjacent structures and nearby teeth [5]. 


\section{Treatment Consideration}

The dentist should consider the following factors to make a treatment decision:

(1) whether the tooth represents a supernumerary or a primary incisor

(2) the degree of tooth mobility

(3) whether the tooth is causing injury to the ventral tongue or the mother's breast [6].

\section{Case Report}

Parents to a newborn of 12 days old reported to the department of Pedodontic and Preventive Dentistry. Mother was concerned about the teeth present on the lower front region of the lower jaw of the baby. She also complained of difficulty in feeding her and fear about is accidental swallowing as the tooth as loosely attached.

On enquiring, parents informed the tooth was present since birth. In the family, no other person has shown similar condition. Prenatal history was non-significant. Child was born after 36 weeks of full term delivery by C- section. On birth, she was healthy except the single unusual finding of natal tooth in mandibular anterior region. On examination, a single natal teeth was present in lower jaw in anterior region. No other intra oral abnormalities except the gum pads being slightly irregular were present. Tooth had grade III mobility and was loosely attached to gum pads. No associated soft tissue swelling, sinus or ulceration was present.

According toSpoug and Feasby classification, it was an immature natal tooth owing to its incomplete or substandard structure, thus indicating a poor prognosis. According to classification of $\mathrm{He}-$ bling (1997), it falls under the category 2 i.e. solid crown poorly fixed to the alveolus by the gingival tissue and little or no root. Also on examination, it was revealed that the tooth had mobility is more than $2 \mathrm{~mm}$, thus indicating the treatment to be extraction.

As the child was born perfectly healthy without any sign of any kind of syndrome, infection or hormonal disturbance; neither she was exposed to any environmental factors like PCB, PCDD, PCDF, thus ruling out these factors causing the condition. Nei- ther the mother faced ill health during pregnancy nor did any other family member have a history of natal teeth. Therefore, the only etiology suspected can be the superficial position of the tooth germ or increased osteoblastic activity in that region.

Clinically, the tooth was of normal size and of normal shape with extremely small root. The colour of crown was whitish opaque color with immature appearance with enamel hypoplasia. Tooth was attached to a pad of soft tissue above the alveolar ridge with exaggerated mobility. Taking the account the young age and difficulty in managing the patient, taking radiograph was difficult. Moreover, owing to the severe mobility and difficulty faced encountered by mother in feeding the child removal of tooth become mandatory irrespective of the tooth being a normal deciduous tooth or a supernumerary one.

The parents were thoroughly informed about the condition, possible etiologies to clear any misconception, various treatment option and consequences of it. Parents were made well aware that the tooth can be one of the milk teeth and its removal may lead to missing of one tooth in the normal set and loss of space which would be eventually regained. They agreed to the treatment plan and provided the necessary consent.

The extraction was scheduled and mother was asked to feed the baby before the procedure. As the child was already more than 10 days, there was no need of prophylactic vitamin $\mathrm{K}$ because the vitamin $\mathrm{K}$ /prothrombin level and $\mathrm{IgG}$ level are that of adult level by this time, which ruled out chances of excessive hemorrhage. All necessary precautions were taken. The infant was kept in the knee-to-knee position under indirect fluorescent ceiling light with the father stabilizing the child head. The concerned area was isolated and dried with cotton rolls. A small amount of topical anesthetic (benzocaine $200 \mathrm{mg} / \mathrm{g}$ ) was sprayed on the gingiva. A piece of gauze piece was inserted in the mouth to prevent any accidental aspiration of the tooth in case it slips and also to keep the working area blood free. Use a periosteal elevator, the surrounding tissue was detached from the tooth. Once the tooth was sufficiently loss, it was pulled out with the help of a gauze piece. Use of forceps was avoided to prevent unneccesary damage. Following extraction, although curetting of the socket is recommended, in this case, the absence of roots in the teeth. A small piece of sterile gauze was placed in the area and slight pressure was applied

Figure 1. Natal tooth prior to extraction.

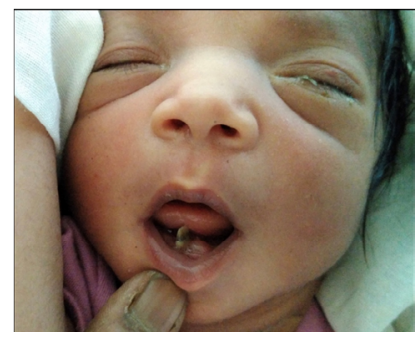

Figure 2. Natal tooth post-extraction.

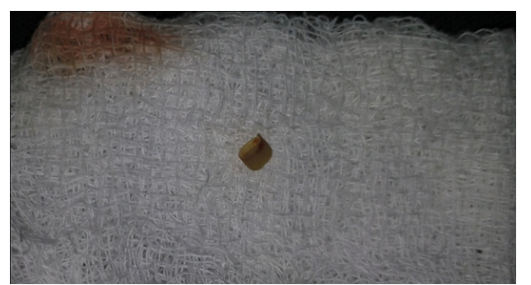


to achieve hemostasis. Later, the mother was given mother was asked to hold it for 20-25 minutes. Once bledding was stopped, the mother was asked to feed the child and the patient was recalled after one week. Follow-up showed the child was normal and absence of any other developmental problems.

\section{Conclusion}

Pediatric dentists should make every effort to educate the parents and the general public on the etiology and clear their myth related to it. We should be aware of the various treatment options and when to apply it. In cases where extraction is chosen, they should be carried out bya pediatric dentist to avoid unnecessary trauma to the area. When saved, periodic follow-up by a pediatric dentist to ensure preventive oral health is very essential. Therefore, to avoid any complication, early diagnosis and adequate treatment is the principle of the management of natal teeth.

\section{References}

[1]. Singh S, Dhananjaya G, Patil R. Reactive fibrous hyperplasia associated with a natal tooth. Journal of the Indian Society of Pedodontics and Preventive Dentistry. 2004 Oct 1;22(4):183-6.

[2]. Maheswari NU, Kumar BP, Karunakaran, Kumaran ST. "Early baby teeth": Folklore and facts. J Pharm Bioallied Sci. 2012 Aug;4(Suppl 2):S329-33. Pubmed PMID: 23066283.
[3]. Mhaske S, Yuwanati MB, Mhaske A, Ragavendra R, Kamath K, Saawarn S. Natal and neonatal teeth: an overview of the literature. ISRN Pediatr. 2013 Aug 18;2013:956269. Pubmed PMID: 24024038.

[4]. Leung AK, Robson WL. Natal teeth: a review. J Natl Med Assoc. 2006 Feb;98(2):226-8. Pubmed PMID: 16708508.

[5]. Rao RS, Mathad SV. Natal teeth: Case report and review of literature. J Oral Maxillofac Pathol. 2009 Jan;13(1):41-6. Pubmed PMID: 21886998.

[6]. Moura LF, Moura MS, Lima MD, Lima CC, Dantas-Neta NB, Lopes TS. Natal and neonatal teeth: a review of 23 cases. J Dent Child (Chic). 2014 May-Aug;81(2):107-11. Pubmed PMID: 25198955.

[7]. Kadam M, Kadam D, Bhandary S, Hukkeri RY. Natal and neonatal teeth among cleft lip and palate infants. Natl J Maxillofac Surg. 2013 Jan;4(1):736. Pubmed PMID: 24163556.

[8]. Chow MH. Natal and neonatal teeth. Journal of the American Dental Association (1939). $1980 \mathrm{Feb}$ 1;100(2):215-6.

[9]. Jasmin JR, Clergeau-Guerithault S. A scanning electron microscopic study of the enamel of neonatal teeth. J Biol Buccale. 1991 Dec;19(4):309-14. Pubmed PMID: 1791169.

[10]. Basavanthappa NN, Kagathur U, Basavanthappa RN, Suryaprakash ST. Natal and neonatal teeth: a retrospective study of 15 cases. Eur J Dent. 2011 Apr;5(2):168-72. Pubmed PMID: 21494384.

[11]. Muench MG, Layton S, Wright JM. Pyogenic granuloma associated with a natal tooth: case report. Pediatr Dent. 1992 Jul-Aug;14(4):265-7. Pubmed PMID: 1303529.

[12]. Kohli K, Christian A, Howell R. Peripheral ossifying fibroma associated with a neonatal tooth: case report. Pediatr Dent. 1998 Nov-Dec;20(7):428-9. Pubmed PMID: 9866149. 